Revista Multidisciplinar do Nordeste Mineiro, v.1, $2021 / 01$

ISSN 2178-6925

\title{
AS CONTRIBUIÇÕES DO BRINCAR PARA O DESENVOLVIMENTO DA CRIANÇA NA EDUCAÇÃO INFANTIL TÍTULO
}

\section{THE CONTRIBUTIONS OF PLAYING FOR CHILDREN'S DEVELOPMENT IN CHILDHOOD EDUCATION TITLE}

\begin{abstract}
Bárbara Costa da Silva
Acadêmica do $8^{\circ}$ Período do curso de Pedagogia, Faculdade Presidente Antônio Carlos-Teófilo Otoni, Brasil. E-mail: Babara.costadasilva@yahoo.com.br

Sandy Kelly Reis Fraga

Acadêmica do $8^{\circ}$ Período do curso de Pedagogia, Faculdade Presidente Antônio

Carlos- Teófilo Otoni, Brasil. E-mail: sandy.ity@hotmail.com
\end{abstract}

Recebido: 10/04/2021 - Aceito10/04/2021

\section{RESUMO}

Nos últimos anos, o lúdico tem recebido maiores destaques em relação a suautilização no contexto educacional, como uma ferramenta ideal para a aprendizagem, por estimular a criança na aquisição de novos conhecimentos e permitir que aprendase divertindo e com atividades adequadas as suas necessidades de aprender, e isso,de forma espontânea e sem cobranças, o que torna a aprendizagem mais atraente e interessante, ampliando assim, as possibilidades para a efetivação do conhecimento. O Referencial Curricular Nacional para a Educação infantil (RCNEl,1998), também faz referência sobre a metodologia e a grade curricular ,que deverá ser adequada a essa faixa etária e as necessidades educacionais desse educando, por isso,considera o "(...)brincar expressando emoções, sentimentos, pensamentos, desejos e necessidades(...)". (BRASIL, 1998) e ainda, que o brincar não deve se restringir somente à sala de aula, mas ser utilizado em ambientes como "(...)o parque ou quintal, envolvendo o reconhecimento do próprio corpo, o do outro, e a imitação podem se transformar em atividades de rotina(...)". (MEC, 1998, p. 45). Logo, é por meio do brincar, que a criança se expressa e ao mesmo tempo aprende, por isso, que atividades lúdicas, como o brincar, ganhou destaque no processo de ensino, enquanto metodologia eficaz em sala de aula, por ser um processo, que acontece de forma prazerosa e significativa para a criança, pois já faz parte da sua vivência, muito antes da escolarização da mesma. Assim, o objetivo deste estudo é apontar como atividades lúdicas, como o brincar, poderão contribuir para o desenvolvimento da criança na Educação infantil. A metodologia utilizada é a bibliográfica, que se refere a pesquisa realizada em livros, artigos e documentos que fundamentam o tema de estudo. Autores estudiosos do tema também foram referenciados, dentre eles estão: Ignachewski (2003), Kishimoto (1994), e outros. O professor possui um papel bem definido nesse processo lúdico de aprendizagem, pois atuará como mediador das atividades, escolhendo o local e as situações metodológicas que melhor envolverá a criança no processo de aprendizagem. A atuação do professor como mediador, tem por finalidade, o alcance dos objetivos educacionais, não sendo, pois, um fim em si 


\title{
$2021 / 01$
}

ISSN 2178-6925

Palavras-Chave: Lúdico. Brincar. Educação Infantil. Escola. Aprendizagem.

\begin{abstract}
In recent years, play has received greater prominence in relation to its use in the educational context, as an ideal tool for learning, as it stimulates children to acquire new knowledge and allows them to learn while having fun and with activities appropriate to their learning needs. learn, and this, spontaneously and without charges, which makes learning more attractive and interesting, thus expanding the possibilities for the realization of knowledge. The National Curriculum Reference for Early Childhood Education (RCNEI, 1998), also makes reference to the methodology and curriculum, which should be appropriate to this age group and the educational needs of this student, therefore, considers the "(...) playing expressing emotions, feelings, thoughts, desires and needs (...) ". (BRASIL, 1998) and also, that playing should not be restricted to the classroom, but should be used in environments such as "(...) the park or yard, involving the recognition of one's own body, that of the other, and imitation can become routine activities (...) ". (MEC, 1998, p. 45). Therefore, it is through playing that the child expresses himself and, at the same time, learns that playful activities, such as playing, gained prominence in the teaching process, as an effective methodology in the classroom, for being a process, that happens in a pleasant and meaningful way for the child, as it is already part of their experience, long before their schooling. Thus, the objective of this study is to point out how playful activities, such as playing, can contribute to the development of children in early childhood education. The methodology used is the bibliographic, which refers to the research carried out on books, articles and documents that support the study theme. Scholarly authors of the theme were also mentioned, among them are: Ignachewski (2003), Kishimoto (1994), and others. The teacher has a well-defined role in this playful learning process, as he will act as a mediator of activities, choosing the location and methodological situations that will best envolve the child in the learning process. The role of the teacher as a mediator has the purpose of achieving educational goals, and is therefore not an end in itself, but a means to achieve those goals.
\end{abstract}

Keywords: Playful. Play. Child education. School. Learning. 


\title{
1. INTRODUÇÃO
}

O termo lúdico tem a sua origem na palavra latina "ludus", que significa, "brincar", e neste "brincar", estão os jogos, brinquedos e divertimentos, compreendendo uma atividade espontânea e prazerosa para quem a pratica. E ainda, refere-se a atividades que envolvem "divertir-se, recrear-se, entreter-se, distrair-se, folgar", "entreter-se com jogos infantis." (FERREIRA, 2003 apud FANTACHOLE, 2011).

Nos últimos anos, o lúdico tem recebido maiores destaques em relação a sua utilização no contexto educacional, como uma ferramenta ideal para a aprendizagem, por estimular a criança na aquisição de novos conhecimentos e permitir que aprenda se divertindo e com atividades adequadas as suas necessidades de aprender, e isso, de forma espontânea e sem cobranças, o que torna a aprendizagem mais atraente e interessante, ampliando assim, as possibilidades para a efetivação do conhecimento.

\begin{abstract}
No que diz respeito aos benefícios cognitivos, brincar contribui para a desinibição, produzindo uma excitação intelectual, altamente estimulante, desenvolvendo habilidades perceptuais, como atenção, desenvolve habilidades de memória, entre outras. Em relação aos benefícios sociais, a criança, por meio do lúdico, representa situações que simbolizam uma realidade que ainda não podem alcançar e aprendem a interagir com as pessoas, compartilhando, cedendo às vontades dos colegas, recebendo e dispensando atenção aos seus pares. Aprendem, ainda, a respeitar e serem respeitados. (BRASIL, 2012c, p. 7).
\end{abstract}

O ato de brincar é tão importante para o desenvolvimento da criança, que vários documentos no Brasil e no mundo, discorreram sobre o assunto, e afirmam, ser um direito da criança ter essa prática, como parte da sua rotina. Dentre os documentos importantes elaborados e que fazem referência ao brincar, está a Declaração Universal dos Diretos da Criança -UNICEF, que afirma que a criança tem o "direito a desfrutar de alimentação, moradia, recreação, ainda em seu princípio VII, estabelece que a criança deve desfrutar plenamente de jogos e brincadeiras". (WIKIPÉDIA,2020 Grifo nosso)

No Brasil, a partir da década de 90, com a Lei de Diretrizes e Bases da Educação Nacional- LDB/1996, o lúdico, passou a ter espaço garantido em sala de aula, sendo respaldado por vários documentos legais, como facilitadores da aprendizagem, por proporcionar o "desenvolvimento físico, emocional, cognitivo e social da criança" (BRASIL,1996), ou seja, o ambiente escolar, deve prover estímulos 
necessários ao desenvolvimento da criança de forma integral, e isso, se referindo ao processo de aprendizagem, que deve ser baseado em atividades lúdicas.

O Referencial Curricular Nacional para a Educação infantil (RCNEI,1998), também faz referência sobre a metodologia e a grade curricular ,que deverá ser adequada a essa faixa etária e as necessidades educacionais desse educando, por isso, considera o "(...)brincar expressando emoções, sentimentos, pensamentos, desejos e necessidades(...)". (BRASIL, 1998) e ainda, que o brincar não deve se restringir somente à sala de aula, mas ser utilizado em ambientes como "(...)o parque ou quintal, envolvendo o reconhecimento do próprio corpo, o do outro, e a imitação podem se transformar em atividades de rotina(...)". (MEC, 1998, p. 45).

Logo, é por meio do brincar, que a criança se expressa e ao mesmo tempo aprende, por isso, que o brincar ganhou destaque no processo de ensino, enquanto metodologia eficaz para sala de aula, por ser um processo, que acontece de forma prazerosa e significativa para a criança, visto que o brincar, já faz parte da sua vivência, muito antes da escolarização da mesma.

\footnotetext{
(...)O brincar é fonte de desenvolvimento e de aprendizagem, constituindo uma atividade que impulsiona o desenvolvimento, pois a criança se comporta de forma mais avançada do que na vida cotidiana, exercendo papéis e desenvolvendo ações que mobilizam novos conhecimentos, habilidades e processos de desenvolvimento e de aprendizagem(...). (VIGOTSKY, 1998, p. 81 apud BIAZOTTO,2014,p.12 ).
}

Diante disso, o presente estudo buscou reunir informações com o propósito de responder ao seguinte problema de pesquisa: Como atividades lúdicas, como o brincar, poderão contribuir para o desenvolvimento da criança na Educação infantil? Assim, o objetivo deste estudo é apontar como atividades lúdicas, como o brincar, poderão contribuir para o desenvolvimento da criança na Educação infantil.

A metodologia utilizada é a bibliográfica, que se refere a pesquisa realizada em livros, artigos e documentos que fundamentam o tema de estudo. Autores estudiosos do tema também foram referenciados, dentre eles estão: Ignachewski (2003), Kishimoto (1994), e outros. O trabalho possui três capítulos, sendo que o primeiro, aborda o conceito de lúdico e um breve histórico nos ambientes escolares ao longo dos anos. O segundo capítulo, refere-se ao histórico da Educação infantil no mundo e no Brasil. Por fim, o terceiro capítulo, aborda as contribuições do brincar para a criança na Educação infantil. 


\title{
1.1 objetivos
}

\subsubsection{Objetivo geral}

- Apontar como atividades lúdicas, como o brincar, poderão contribuir para o desenvolvimento da criança na Educação infantil.

\subsubsection{Objetivos específicos}

- Conceituar o termo lúdico;

- Conhecer a Histórico da educação infantil e as legislações pertinentes;

- Apontar as contribuições do brincar para a criança na Educação Infantil.

\section{LUDICIDADE: CONCEITO E BREVE HISTÓRICO}

O termo lúdico tem a sua origem na palavra latina "ludus", que significa, "brincar", e neste "brincar", estão os jogos, brinquedos e divertimentos, compreendendo uma atividade espontânea e prazerosa para quem a pratica. E ainda, refere-se a atividades que envolvem "divertir-se, recrear-se, entreter-se, distrair-se, folgar", "entreter-se com jogos infantis." (FERREIRA, 2003 apud FANTACHOLE, 2011).

Outra definição para o termo lúdico, está Santos (2007), ao ensinar que o lúdico, é uma necessidade inerente a qualquer indivíduo, independente da faixa etária.

\begin{abstract}
"A ludicidade é uma necessidade do ser humano em qualquer idade e não pode ser vista apenas como diversão. O desenvolvimento do aspecto lúdico facilita a aprendizagem, o desenvolvimento pessoal, social e cultural, colabora para uma boa saúde mental, prepara para um estado interior fértil, facilita os processos de socialização, comunicação, expressão e construção do conhecimento". (SANTOS, 2007, p 12).
\end{abstract}

Sendo importante ressaltar, que o lúdico, faz parte da história da humanidade, pois de acordo com KIschimoto (1993), na Antiguidade Clássica, os filósofos e educadores Aristóteles e Platão, defendiam o Jogo como Metodologia de Ensino.

Platão foi o principal deles e forma, com Aristóteles, as bases do pensamento ocidental. A educação, segundo a concepção platônica, deveria testar as aptidões do aluno (...) formulou modelos para o ensino por que considerava ignorante a sociedade grega de seu tempo. Por seu lado, Aristóteles, que foi discípulo de Platão, planejou um sistema de ensino bem mais próximo do que 


\section{$2021 / 01$}

ISSN 2178-6925

se praticava realmente na Grécia de então, equilibrado entre as atividades físicas e intelectuais e acessível a grande número de pessoas. ((KISCHIMOTO, 1993 apud FERRARI ,2003, p.7)

Na Idade Média, também há registros, que o jogo era utilizado como um meio de promover o entretenimento social, sendo permitido, no entanto, somente para os homens, pois as mulheres e crianças nessa época, viviam à margem da sociedade.

Conforme afirma Ariés (1981):

Na Idade Média, os jogos eram basicamente destinados aos homens, visto que as mulheres e as crianças não eram consideradas cidadãos e, por conseguinte, estando sempre à margem, não participavam de todas as atividades organizadas pela sociedade. Porém, em algumas ocasiões nas quais eram realizadas as festas da comunidade, o jogo funcionava como um grande elemento de união entre as pessoas. (ARIÉS,1981 apud SOUZA,2015,p.2)

Percebe-se, que na Idade Média, o lúdico era considerado apenas uma atividade de lazer coletivo, dentre os jogos mais utilizados na época, estão: o "Bilboquê, chicote queimado, quebra cabeça, cara ou coroa e trunfo". (KISHIMOTO,2006) A concepção a respeito do lúdico, como recurso auxiliar à aprendizagem, foi desenvolvida anos depois.

No Brasil, os índios, portugueses e os negros, foram os precursores dos jogos e brincadeiras que são utilizados na educação nos dias de hoje, frutos da miscigenação de raças. (KISHIMOTO , 1999, p.17)

\footnotetext{
“(...)O primeiro (índios) contribuiu por meio de atividades praticadas como caçar, pescar, dançar e entre outros, tinham de forma intrínseca e praticada pelos jogos, brinquedos e brincadeiras, portanto ligado à sua sobrevivência. Já O segundo (portugueses) faziam uso dos jogos, brinquedos e brincadeiras para seu desenvolvimento intelectual e diversão, como canções de roda, lendas, jogos de bolinhas de gude, pião, amarelinha, a pipa, dentre outros. E por fim os negros, que mesmo com toda repressão, preocupavam-se com cultura, lazer e educação, para desenvolver o convívio social. (...)" (AMARANTE, 2019, p.33)
}

Em meados do século XV, atividades lúdicas, eram utilizadas, como metodologia e estratégia de ensino nos colégios jesuítas, mas com a expulsão dos jesuítas, a Igreja Católica aboliu qualquer atividade de cunho lúdico, por considerar profanas, a partir de então, não mais se ouviu falar do lúdico no contexto educacional. (ANNA; NASCIMENTO, 2011)

A partir da década de 90, com a Lei de Diretrizes e Bases da Educação Nacional- LDB/1996, o lúdico, passou a ter espaço garantido em sala de aula, sendo respaldado por vários documentos legais, como facilitadores da aprendizagem, por 


\section{$2021 / 01$}

ISSN 2178-6925

proporcionar o "desenvolvimento físico, emocional, cognitivo e social da criança" (BRASIL,1996), ou seja, o ambiente escolar, deve prover os estímulos necessários para o desenvolvimento da criança, visto que o processo de aprendizagem, deve ser baseado em atividades lúdicas.

\section{HISTÓRICO DA EDUCAÇÃO INFANTIL E AS LEGISLAÇÕES PERTINENTE}

Durante um longo período da história da humanidade, a criança era vista como um ser inferior e oposto ao adulto, desprovido qualquer capacidade, devido à pouca idade, não havendo por isso, a preocupação com a educação e escolarização das mesmas. Mas a partir do século XVIII, começa a haver uma preocupação com a criança, seu desenvolvimento e uma nova concepção sobre a infância, chamada de "Puericultura", que é o acompanhamento do desenvolvimento infantil, tendo como marco, a criação das Casas de Expostos, responsáveis por cuidar das crianças em questões relacionadas a higiene, vacinação, alimentação e prevenção de doenças. ( SILVA,2013,p.12)

Sobre a Casa (Roda) dos expostos:

“(...) A roda dos expostos, como assistência caritativa, era, pois, missionária. A primeira preocupação do sistema para com a criança nela deixada era de providenciar o batismo, salvando a alma da criança, a menos que trouxesse consigo um bilhete - o que era muito comum - que informava à rodeira de que o bebê já estava batizado. No caso de dúvida dos responsáveis pela instituição, a criança era novamente batizada. Mas o fenômeno de abandonar os filhos é tão antigo como a história da colonização brasileira, só que antes da roda, as crianças eram abandonadas e supostamente assistidas pelas municipalidades, ou pela compaixão de quem as encontrava. (AQUINO ,2001, p. 31 apud FILIPIM;ROSSI;RODRIGUES, 2017, p.4)

Vale ressaltar, que a Casa dos expostos, ou roda dos expostos, era um local para abrigar crianças pobres e rejeitadas por suas famílias, sendo instituições mantidas por “(...)doações de alguns nobres, por autorização do Rei e consentimento dos dirigentes da Santa Casa".( MAFRON, 2012, p.87)

crianças enjeitadas nas Rodas eram alimentadas por amas-de-leite alugadas e também entregues a famílias, mediante pequenas pensões. Em geral, a assistência prestada pela Casa dos Expostos perdurava em torno de sete anos. A partir daí, a criança ficava, como qualquer outro órfão, à mercê da determinação do juiz, que decidia sobre seu destino de acordo com os interesses de quem o quisesse manter. Era comum que fossem utilizadas 


\title{
$2021 / 01$
}

ISSN 2178-6925

para o trabalho desde pequenas (RIZZINI, 2009, p. 19 apud MAFRON, 2012, p.87).

Logo, o século XVIII, foi um divisor de águas para a infância, devido a nova concepção sobre os cuidados que deveria proporcionar para a criança, assim, ela passou a ter um novo lugar na sociedade, e passa a ser vista, como um ser de direitos , merecedora de respeito, educação, escolarização e um ensino que considere suas particularidades e características próprias.

Impulsionados por essa nova concepção, surge o primeiro jardim de infância de caráter privado no país, fundado no Rio de Janeiro, em 1875, pelo médico Joaquim José Menezes Vieira e sua esposa D. Carlota de Menezes Vieira. Por ser uma instituição privada, tinha como público principal, a clientela rica e crianças do sexo masculino.

Assim,

\begin{abstract}
Em 1875 instala, juntamente com sua esposa, D. Carlota de Menezes Vieira, um jardim de crianças no Colégio Menezes Vieira, situado na rua dos Inválidos, №. 26, em um dos melhores bairros da cidade do Rio de Janeiro, com ótimas instalações - um pavilhão hexagonal, especialmente construído no centro do jardim, com ar e luz por quatro janelas. O jardim tem por objetivo servir uma clientela de elite, atendendo a crianças do sexo masculino, de 3 a 6 anos, que se iniciam em atividades relacionadas à ginástica, à pintura, ao desenho, aos exercícios de linguagem e de cálculo, escrita, leitura, história, geografia e religião. (BASTOS, 2001, p. 32 apud FILIPIM; ROSSI; RODRIGUES, 2017, p.5)
\end{abstract}

Já no ano de 1879, com a Reforma Leôncio de Carvalho, tornou-se obrigatório, o ensino primário e a criação de um jardim de infância por todo o império para a educação de criança antes de sete anos, porém, essa iniciativa, não recebia muitos investimentos financeiros por parte do governo da época.

No entanto, como marco inicial, para surgimento da Educação infantil no país, considera-se, o ano de 1899, com a criação de duas instituições voltadas para essa finalidade, a fundação do Instituto de Proteção e Assistência à Infância e a creche da Companhia de Fiação e Tecidos Corcovado, ambas no Rio de Janeiro. (KUHLMANN JR. 2007 apud SILVA; SOUZA, 2017)

O pediatra e higienista Arthur Moncorvo Filho, foi o idealizado do Instituto de Proteção e Assistência à Infância do Brasil, no ano de 1880, e contou com a participação da elite e intelectuais da época, sendo utilizado sua própria residência como sede do instituto. (NUNES; CORSINO; DIDONET, 2011, p.19) 


\section{$2021 / 01$}

ISSN 2178-6925

A malha assistencial concebida por Moncorvo Filho instituiu efeitos e consequências no que tange à colaboração para a difusão de um pensamento higienista, mas também para a organização das instituições públicas no atendimento à infância, Para instituir uma obra consequente e promotora de efeitos na esfera social, Moncorvo Filho associou-se a outros homens de ciências, entre eles, destacaram-se Nascimento Gurgel, Leão de Aquino, Eduardo Meireles, Jefferson de Lemos, Luís Bulcão, Leonel Rocha e Magalhães Penido. Assim, a cruzada em prol da infância pobre da capital do país congregou homens e mulheres das elites identificadas com a crença de que a solução para os problemas deveria advir de um combate "sem tréguas" em prol da assistência e da educação das crianças. Por meio da composição de uma rede de sociabilidade, esses homens e mulheres conceberam o instituto como lugar de aglutinação de iniciativas filantrópicas (CAMARA, 2014, p. 78 apud GOLINELLI, 2017, p.4)

Os objetivos do Instituto de Proteção e Assistência à Infância do Brasil, eram amplos, pois a finalidade era acolher qualquer criança, independente da condição social e limitações existentes.

“(...) Ao Instituto foram atribuídos objetivos bastante amplos e diversificados: (a) atender aos menores de 8 anos, (b) elaborar leis que regulassem a vida e a saúde dos recém-nascidos, (c) regular o serviço das amas de leite, (d) velar pelos menores trabalhadores e criminosos, (e) atender as crianças pobres, doentes, defeituosas, maltratadas e moralmente abandonadas, (f) criar maternidades, creches e jardins de infância. NUNES; CORSINO; DIDONET, 2011, p.20)

De acordo com a autora Câmara (2014), a proposta da instituição criada por Moncorvo Filho, era suprir as necessidades básicas, tais como alimentação, roupas e saúde, cuidados estes, que as crianças que frequentavam seu instituto eram desprovidas, por serem de famílias pobres e sem instrução.

A orientação proposta por Moncorvo Filho ao conceber a instituição, assentava-se na ideia corrente, à época, de que a razão médica deveria prevalecer sobre as diversas formas de organização da cidade e dos indivíduos. Dessa forma, ao longo de sua existência, de 1899 a 1939, o instituto colocou em prática um conjunto de procedimentos tendentes a produzir, difundir e preceituar os conhecimentos de higiene, de puericultura, de proteção, de cuidados e de educação com relação à construção da "criança" (CAMARA, 2013, p. 2)

Já no ano de 1899, Rio de Janeiro, surgem as primeiras creches e pré escolas, na Fábrica de Tecidos Corcovado, com a finalidade somente de atender aos funcionários da fábrica, que precisavam de um local que funcionasse em período integral, para cuidar de seus filhos. É importante salientar, que as creches e pré- 


\title{
$2021 / 01$
}

ISSN 2178-6925

escolas, eram vistas como uma Casa de Exposto aperfeiçoada, por atuar ainda, de maneira assistencialistas. (LIMA, 2012, p. 20)

\begin{abstract}
“(...) A creche, para as crianças de zero a três anos, foi vista como muito mais do que um aperfeiçoamento das Casas de Expostos, que recebiam as crianças abandonadas; pelo contrário, foi apresentada em substituição ou oposição a estas, para que as mães não abandonassem suas crianças. Além disso, não se pode considerar a creche como uma iniciativa independente das escolas maternais ou jardins de infância, para as crianças de três ou quatro a seis anos, em sua vertente assistencialista, pois as propostas de atendimento educacional à infância de zero a seis anos tratam em conjunto das duas iniciativas, mesmo que apresentando instituições diferenciadas por idades e classes sociais. (KUHLMANN , 2010, p. 78 apud MENDES, 2015, p. 4)
\end{abstract}

As décadas de 40 e 60, foi denominada por alguns autores de "populismo", por ter como características, a ênfase em políticas públicas voltadas para a população, e principalmente, para o trabalhador, que passou a ter seus direitos trabalhistas oficializados, com a promulgação da Consolidação das leis Trabalhistas-CLT (1943), ao estabeleceu os direitos da mãe trabalhadora. Sendo assim, com a Consolidação das leis Trabalhistas-CLT (1943), as empresas com mais de trinta funcionárias, foram obrigadas a manter creches ou instituições para essa finalidade. (MARAFON, 2012, p.108)

Conforme o texto do Decreto-lei ํㅜ 5.452, de 1ํ de maio de 1943 (CLT):

. $\S 1^{0}$ - Os estabelecimentos em que trabalharem pelo menos 30 (trinta) mulheres com mais de 16 (dezesseis) anos de idade terão local apropriado onde seja permitido às empregadas guardar sob vigilância e assistência os seus filhos no período da amamentação.( BRASIL, 1943)

Com o aumento de profissionais mulheres nas empresas e indústrias, na década de 60, também houve o aumento da demanda por creches e pré escolas, diante disso, o poder público precisou intervir com a criação de mais instituições infantis públicas, para atender essa demanda. Por isso, em 1961, através da Lei de Diretrizes e Bases da Educação Nacional no 4024/61, o jardim de infância público, recebeu amparo legal através do artigo. 23 e 24. (OLIVEIRA, 2002, p.102 apud MARAFON, 2012, p.15)

"Art. 23. A educação pré-primária destina-se aos menores de até 7 anos, e será ministrado em escolas maternais ou jardins-de-infância.

Art. 24. As empresas que tenham a seu serviço mães de menores de sete anos serão estimulados a organizar e manter, por iniciativa própria ou em 


\title{
$2021 / 01$
}

ISSN 2178-6925

cooperação com os poderes públicos, instituições de educação pré-primária." (BRASIL, 1961)

Mas somente na década de 80 , que a Educação infantil ganhou maiores destaques no cenário nacional, e um novo conceito, advindo da Constituição Federal de 1988. Sobre a importância da Constituição Federal de 1988 para a Educação infantil, o autor Kuhlmann, (2003, p.469) ensina:

\begin{abstract}
Pode-se falar de Educação infantil em um sentido bastante amplo, envolvendo toda e qualquer forma de educação da criança na família, na comunidade, na sociedade e na cultura em que viva. Mas há outro significado, mais preciso e limitado, consagrado na Constituição Federal de 1988, que se refere à modalidade específica das instituições educacionais para a criança pequena, de 0 a 6 anos de idade. Essas instituições surgem durante a primeira metade do século XIX, em vários países do continente europeu, como parte de uma série de iniciativas reguladoras da vida social, que envolvem a crescente industrialização e urbanização. (KUHLMANN, 2003,p. 469 apud BARRETO; SILVA; MELO,2008, p.2)
\end{abstract}

É possível afirmar, que a Constituição Federal de 1988, foi um documento decisivo para a Educação infantil no âmbito nacional, pois foi garantido por meio dela, pela primeira vez na história da Educação infantil brasileira, o "direito das crianças de 0 a 6 anos frequentarem creches e pré-escolas" e estabelecer, "o dever do Estado com a educação será efetivado mediante a garantia de [...] atendimento em creche e pré-escola às crianças de zero a seis anos de idade" (BRASIL, 1988). Em 1990, corroborando com a Constituição de 1988, foi criado o Estatuto da Criança e do Adolescente que veio reafirmar no capítulo IV, artigo 54, inciso IV o direito a educação e escolarização, para as crianças de 0 a 6 anos ao atendimento em creches e préescolas de caráter público.(ECA, 1990)

Com a Lei de Diretrizes e Bases da Educação 9394/96, criada em 20 de dezembro de 1996, a Educação infantil no sistema nacional de ensino, passou a ser considerada a primeira etapa da educação básica, tendo como finalidade, o desenvolvimento integral da criança de 0 a 6 anos de idade.

Art.29. A Educação infantil, primeira etapa da educação básica, tem como finalidade o desenvolvimento integral da criança até cinco anos de idade, em seus aspectos físico, psicológico, intelectual e social, completando a ação da família e da comunidade.

Art.30. A Educação infantil será oferecida em: Creches, ou entidades equivalentes, para a criança de até três anos de idade; Pré - escolas, para as crianças de até três anos de idade; 


\section{1/01}

ISSN 2178-6925

Art.31. Na Educação infantil a avaliação far-se-á medida acompanhamento e registro do seu desenvolvimento, sem o objeto de promoção mesmo para o acesso ao ensino fundamental (BRASIL, 1996, p.20)

Portanto, a modelo de Educação infantil da atualidade, nasceu das primeiras iniciativas em prol da valorização da infância e da educação e escolarização da criança, que através das iniciativas privadas e governamentais, garantiu o direito da criança frequentar uma escola, conforme estabelecido pela Constituição Federal de 1988. Segundo o autor Ferreira (2000), a entrada da criança na escola, é um marco importante para seu desenvolvimento, pois são nesses locais que ela receberá os primeiros ensinamentos, pois a escola é "(..)o local onde se realiza a socialização secundária das crianças e se assiste ao processo da sua escolarização, ou seja, onde se processa a aprendizagem" da trilogia: leitura, escrita e cálculo, bases fundamentais para aceder à cultura letrada". (FERREIRA, 2000 apud SILVA,2013,p.15)

\section{AS CONTRIBUIÇÕES DO BRINCAR PARA A CRIANÇA NA EDUCAÇÃO INFANTIL}

Nos últimos anos, o lúdico tem recebido maiores destaques em relação a sua utilização no contexto educacional, como uma ferramenta ideal para a aprendizagem, por estimular a na aquisição de novos conhecimentos e permitir, que a criança aprenda se divertindo e com atividades adequadas as suas necessidades de aprender, e isso, de forma espontânea e sem cobranças, o que torna a aprendizagem mais atraente e interessante, ampliando assim, as possibilidades para a efetivação do conhecimento.

[...] do ponto de vista físico, cognitivo e social as brincadeiras trazem grandes benefícios para a criança. Como benefício físico, o lúdico satisfaz as necessidades de crescimento da criança, de desenvolvimento das habilidades motoras, de expressão corporal.No que diz respeito aos benefícios cognitivos, brincar contribui para a desinibição, produzindo uma excitação intelectual, altamente estimulante, desenvolvendo habilidades perceptuais, como atenção, desenvolve habilidades de memória, entre outras. Em relação aos benefícios sociais, a criança, por meio do lúdico, representa situações que simbolizam uma realidade que ainda não podem alcançar e aprendem a interagir com as pessoas, compartilhando, cedendo às vontades dos colegas, recebendo e dispensando atenção aos seus pares. Aprendem, ainda, a respeitar e serem respeitados. (BRAINER et all, 2012, p. 7 apud VELOSO; MACHADO, 2017, p.10). 
É neste sentido, que o brincar contribui para a construção do conhecimento, por potencializa o processo de aprendizagem, sendo um facilitador e recurso pedagógico, que na concepção de Piaget (1978) , "a criança, quando brinca, assimila o mundo do seu jeito sem compromisso com a realidade, devido a sua interação com o objeto não vai depender da natureza do objeto, mas da função que a criança the der(...)".(PIAGET, 1978 apud SOUZA, 2007, p.22)

Logo, é por meio do brincar, que a criança se expressa e ao mesmo tempo aprende, por isso, que atividades lúdicas, como o brincar, ganhou destaque no processo de ensino, enquanto metodologia eficaz em sala de aula, por ser um processo, que acontece de forma prazerosa e significativa para a criança, pois já faz parte da sua vivência, muito antes da escolarização da mesma.

(...)O brincar é fonte de desenvolvimento e de aprendizagem, constituindo uma atividade que impulsiona o desenvolvimento, pois a criança se comporta de forma mais avançada do que na vida cotidiana, exercendo papéis e desenvolvendo ações que mobilizam novos conhecimentos, habilidades e processos de desenvolvimento e de aprendizagem(...). (VIGOTSKY, 1998, p. 81 apud BIAZOTTO,2014,p.12 ).

Ainda segundo Vygotsky (1998, p.81):

“(...) O brincar relaciona-se ainda com a aprendizagem. Brincar é aprender; na brincadeira, reside a base daquilo que, mais tarde, permitirá à criança aprendizagens mais elaboradas. O lúdico torna-se, assim, uma proposta educacional para o enfrentamento das dificuldades no processo ensinoaprendizagem".( VYGOTSKY 1998 apud ROLIN; GUERRA; TASSIGNY, 2008,p.1)

Dessa maneira, o brincar deixa de ser apenas uma atividade de recreação e entretenimento, pois na concepção do autor Oliveira (2000, p. 67), está intimamente ligado ao "desenvolver-se integralmente".

“(..) O brincar não significa apenas recrear, é muito mais, caracterizando-se como uma das formas mais complexas que a criança tem de comunicar-se consigo mesma e com o mundo, ou seja, o desenvolvimento acontece através de trocas recíprocas que se estabelecem durante toda sua vida. Assim, através do brincar a criança pode desenvolver capacidades importantes como a atenção, a memória, a imitação, a imaginação, ainda propiciando à criançao desenvolvimento de áreas da personalidade como afetividade, motricidade, inteligência, sociabilidade e criatividade(...)". (OLIVEIRA, 2000, p. 67 apud FANTACHOLE, 2011, p. 1) 
Isto posto, o ato de brincar é tão importante para o desenvolvimento integral da criança, que vários documentos no Brasil e no mundo, discorreram sobre o assunto, e afirmaram ser um direito da criança, ter essa prática como parte da sua rotina. Dentre os documentos importantes elaborados e que fazem referência a ludicidade na infância, está a Declaração Universal dos Diretos da Criança -UNICEF, que afirmaque a criança tem o "direito a desfrutar de alimentação, moradia, recreação, ainda emseu princípio VII, estabelece que a criança deve desfrutar plenamente de jogos e brincadeiras". (WIKIPÉDIA,2020 Grifo nosso)

Outro documento importante, é a Declaração Universal dos Direitos das Crianças(1959).

Princípio IV - A criança terá direito a desfrutar de alimentação, moradia, lazer e serviços médicos adequados.

Princípio VII - A criança deve desfrutar plenamente de jogos e brincadeiras os quais deverão estar dirigidos para educação; a sociedade e as autoridades públicas se esforçarão para promover o exercício deste direito.(UNICEF, 2009 p.2 apud WIKIPÉDIA,2020)

Diante das contribuições do brincar para a criança, e em específico, para a aprendizagem na Educação infantil, conforme citado pelos documentos a nível mundial, no Brasil, a Constituição da República Federativa do Brasil de 1988, em seu capítulo II, estabeleceu os direitos sociais de todo cidadão brasileiro.

Dos Direitos Sociais Art. 6ำ São direitos sociais a educação, a saúde, o trabalho, a moradia, o lazer, a segurança, a previdência social, a proteção à maternidade e a infância, a assistência aos desamparados, na forma desta constituição (BRASIL, 2008, p.14 grifo nosso).

Conforme expresso pela Constituição de 1988, a educação é um direito de todos, no entanto, há também os direitos sociais, que aborda o lazer, como atividade garantida, independentemente de raça, sexo ou qualquer outra diferença de cunho social, sendo pois de responsabilidade do poder público e da família, a efetivação dessas garantias constitucionais. (BRASIL.1988)

A educação, direito de todos e dever do Estado e da família, será promovida e incentivada com a colaboração da sociedade, visando ao pleno desenvolvimento da pessoa, seu preparo para o exercício da cidadania e sua qualificação para o trabalho (BRASIL, 2008, p. 135).

Nessa mesma concepção, a Lei no 8.069/1990, responsável pela instituição do Estatuto da Criança e do Adolescente (ECA), criado com o objetivo de proteger 
integralmente a criança e do adolescente, também estabelece em seu Art. 4ํㅜ e 59, que "a criança tem direitos referentes a educação, ao esporte, ao lazer e é dever dos municípios, dos estados e da União destinarem de recursos e espaços para programações culturais, esportivas e de lazer voltadas para a infância e a juventude". (ECA,1990 grifo nosso)

Percebe-se, que tanto a Constituição de 1988, carta magna do país, quanto o Estatuto da Criança e do Adolescente (ECA), reconheceram atividades de cunho lúdicas, como fundamentais e direito garantindo da criança. Outras leis e diretrizes educacionais também foram elaboradas, a partir dos documentos referenciados, estabelecendo como obrigatório para o contexto da Educação infantil a ludicidade como metodologia de ensino.

Dentre as leis e diretrizes elaboradas, está a Lei de Diretrizes e Bases da Educação 9394/96, de 20 de dezembro, responsável pela organização do sistema de ensino, um documento norteador na Educação infantil, pois a partir dessa lei, que surgiu o Referencial Curricular Nacional para a Educação infantil (RCNEI,1998), que faz referência sobre a metodologia e a grade curricular ,que deverá ser adequada a essa faixa etária e as necessidades educacionais desse educando, por isso,considera o “(...)brincar expressando emoções, sentimentos, pensamentos, desejos e necessidades(...)". (BRASIL, 1998) e ainda, que o brincar não deve se restringir somente à sala de aula, mas ser utilizado em ambientes como "(...)o parque ou quintal, envolvendo o reconhecimento do próprio corpo, o do outro, e a imitação podem se transformar em atividades de rotina(...)". (MEC, 1998, p. 45).

As Diretrizes Curriculares Nacionais para a Educação infantil, que define os princípios norteadores que permitam o processo de formação ética, política e estética da criança, também ressalta a "ludicidade e a expressividade infantis", como parte primordial para o trabalho pedagógico na Educação infantil, pois "nessa etapa devese assumir o cuidado e a educação, valorizando a aprendizagem para a conquista da cultura da vida, por meio de atividades lúdicas em situações de aprendizagem (jogos e brinquedos)". (BRASIL,2013)

Frente ao exposto, o professor possui um papel bem definido nesse processo lúdico de aprendizagem, pois atuará como mediador das atividades, escolhendo o local e as situações metodológicas que melhor envolverá a criança no processo de aprendizagem. A atuação do professor como mediador, tem por finalidade, o alcance 


\title{
2021/01
}

ISSN 2178-6925

dos objetivos educacionais, não sendo, pois, um fim em si mesmo, mas um meio para o alcance desses objetivos.

\begin{abstract}
Cabe ao professor organizar situações para que as brincadeiras ocorram de maneira diversificada para propiciar às crianças a possibilidade de escolherem temas, papéis, objetos e companheiros com quem brincar ou jogos de regras e construção, e assim elaborarem de forma pessoal e independente suas emoções, sentimentos, conhecimentos e regras sociais(...). (RCNEI, 1998, p.29).
\end{abstract}

Sendo assim, o brincar é um recurso pedagógico que deve ser introduzido na prática de ensino de maneira permanente, devido aos inúmeros benefícios para a criança, contribuindo não somente para a aprendizagem, mas para o desenvolvimento físico, intelectual e social, por isso, as atividades de cunho lúdico, ganham espaço nos ambientes escolares.

Portanto, o lúdico na Educação infantil tem seu espaço na Educação infantil.

Ganha espaço, como ferramenta ideal da aprendizagem, na medida em que propõe estímulo ao interesse do aluno, desenvolve níveis diferentes de sua experiência pessoal e social, ajuda-o a construir novas descobertas, desenvolve e enriquece sua personalidade e simboliza um instrumento pedagógico que leva ao professor a condição de condutor, estimulador e avaliador da aprendizagem. (ANTUNES ,1998, p. 36 apud SANTOS; ZÓIA 2000, p. 2)

Por isso, para o autor Almeida (2009, p.01), a sala de aula é um lugar de brincar, pois é possível o professor conciliar a teoria com a prática como forma de assimilação e aprendizagem.

Sala de aula é um lugar de brincar se o professor consegue conciliar o objetivo pedagógico com os desejos do aluno. Para isso é necessário encontrar equilíbrio sempre móvel entre o cumprimento de suas funções pedagógicas e contribuir para o desenvolvimento da subjetividade, para a construção do ser humano autônomo e criativo. Credita ao aluno, isto é, 'a sua ação, à parte de responsabilidade no desenvolvimento. Mesmo procurando fazer sua parte, o professor e a escola dão/respeitam a possibilidade de que outra coisa aconteça (ALMEIDA, 2009, p.01 apudJARDIM et.al. ,2014 p.11)

Portanto, por meio dos autores e documentos citados, é possível afirmar, que o brincar, na Educação infantil , tem o seu lugar de destaque enquanto ferramenta pedagógica e recurso eficaz, ao permitir, que a criança se relacione com outras crianças, adultos, e ainda, desenvolva a aprendizagem de maneira estimulante e prazerosa para elas. 


\section{Considerações Finais}

O objetivo deste estudo é apontar como atividades lúdicas, como o brincar, poderão contribuir para o desenvolvimento da criança na Educação infantil. É sabido, que a Educação infantil enquanto etapa mais importante da educação básica, conforme citado pela Lei de Diretrizes e Bases da Educação 9394/96, necessita de ferramentas que contribua para a aprendizagem da criança, por ser tudo muito novo para a criança.

O estudo mostrou que o brincar nessa faixa etária é umas das experiências mais satisfatória para a criança, e por isso, quando incorporado ao ambiente escolar, contribui com inúmeros resultados que vão além de entretenimento, mas no desenvolvimento integral da criança. Portanto, frente ao exposto, a escola e os educadores deveriam aproveitar mais esse potencial educativo próprio do brincar, que oportuniza o desenvolver e a socialização por meio do brincar. 


\section{Referências}

AMARANTE, Antônia DA Silva. Jogos, brinquedos e brincadeiras na educação infantil: possibilidades de desenvolvimento e aprendizagens. Disponível em:< https://repositorio.ifgoiano.edu.br/bitstream/prefix/1090/1/TC_PEDAGOGIA_ANTONI A\%20AMARANTE.pdf> Acesso em: 18 agost.2020.

ARIÉS, Philippe. História Social da Criança e da Família. 2. ed. Tradução de Dora Flaksman. Rio de Janeiro: LTC Editora, 1981.

BARRETO, Luciani Gallo Machado; SILVA, Neide; MELO, Solange dos Santos. A história da educação infantil: Centro de Educação infantil Eusébio Justino de Camargo Nova Olímpia - MT. Disponível em:< need.unemat.br/4_forum/artigos/luciani.pdf > Acesso em: 02 set.2020.

BIAZOTTO, Lilian. A brincadeira e o desenvolvimento da criança na educação infantil. Disponível em:<http://repositorio.roca.utfpr.edu.br/jspui/bitstream/1/4396/1/MD_EDUMTE_2014 2_51.pdf>Acesso em: 01 out.2020.

BRASIL. Constituição da República Federativa do Brasil de 1988. Disponível em:< http://www.planalto.gov.br/ccivil_03/constituicao/constituicaocompilado.htm > Acesso em: 02 out.2020.

BRASIL. lei no 4.024, de 20 de dezembro de 1961. Disponível em: < http://www.planalto.gov.br/ccivil_03/Leis//4024.htm> Acesso em: 02 out.2020.

BRASIL. Decreto-lei no 5.452, de 1ㅇde maio de 1943. Disponível em:<http://www.planalto.gov.br/ccivil_03/decreto-lei/del5452.htm> Acesso em: 31 agost. 2020 .

BRASIL. Diretrizes Curriculares Nacionais da Educação Básica. Disponível em:< http://confinteabrasilmais6.mec.gov.br/images/documentos/diretrizes_curiculares_na cionais_educacao_basica.pdf> Acesso em: 25 nov.2018.

BRASIL. Estatuto da criança e do Adolescente. Brasília. Lei 8069, 13 de julho 1990. Constituição e Legislação relacionada. São Paulo. Cortez.

BRASIL.Lei no 9.394, de 20 de dezembro de 1996. Disponível

em:<http://www.planalto.gov.br/ccivil_03/leis//9394.htm> Acesso em: 11 agost.2020. 
CÂMARA, Sônia. Por uma Ação Preventiva da Infância: as Conferências de Higiene Infantil do Instituto de Proteção e Assistência à Infância do Rio de Janeiro (1901 a 1907).Disponível em:< http://www.snh2013.anpuh.org/resources/anais/27/1370987137_ARQUIVO_copiaen viadaANPUH.pdf> Acesso em: 15 Out.2020..

FANTACHOLE, Fabiane das Neves . O Brincar na Educação Infantil: Jogos, Brinquedos e Brincadeiras: Um Olhar Psicopedagógico. Disponível em:< http://revista.fundacaoaprender.org.br/?p=78> Acesso em: 20 agost.2020.

FERNANDEZ, Sandra Cristina.Reflexão Sobre o Brincar na Educação Infantil. Disponível em:<https://www.pedagogia.com.br/artigos/reflexaobrincar/> Acesso em: 01 out.2020.

FILIPIM, Priscila Viviane de Souza; ROSSI, Ednéia Regina; RODRIGUES, Elaine . História da institucionalização da educação infantil: dos espaços de assistência à obrigatoriedade de ensino (1875-2013. Disponível em:< file:///C:/Users/User/AppData/Local/Packages/Microsoft.MicrosoftEdge_8wekyb3d8b bwe/TempState/Downloads/8650411-Texto\%20do\%20artigo-32269-1-1020171020\%20(1).pdf> Acesso em: 31 agost.2020.

GOLINELLI, Juliane Rembis Costa. "À cruzada pela infância" - o instituto de proteção e assistência à infância do Rio de Janeiro. Disponível em:< https://educere.bruc.com.br/arquivo/pdf2017/25381_14202.pdf> Acesso em: 28 set.2020.

KISHIMOTO, Tizuko Morchida. (Org.) Jogo, brinquedo, brincadeira e a educação. 4. ed. São Paulo: Cortez, 2006.

KISHIMOTO, Tizuka Morchida. Jogos Infantis; O jogo, a criança e a educação. 6 ed. Petrópolis: Vozes, 1999.p.17.

MARAFON, Danielle. Educação infantil no Brasil: um percurso histórico entre as ideias e as políticas públicas para a infância. Disponível em:< www.histedbr.fe.unicamp.br/acer_histedbr/seminario/seminario8/_.../ZjxYEbbk.doc> Acesso em: 28 set.2020.

MEC, Ministério da Educação e Cultura. Referencial curricular nacional para a Educação Infantil: Introdução I. Disponível em:< http://portal.mec.gov.br/seb/arquivos/pdf/rcnei_vol1.pdf> Acesso em: 02 out.2020.

MEC, Ministério da Educação e Cultura. Pacto Nacional pela Alfabetização na Idade Certa: LUDICIDADE NA SALA DE AULA. Disponível em:< http://www.piraquara.pr.gov.br/aprefeitura/secretariaseorgaos/educacao/uploadAddr ess/Unidade_04_Ano_01\%5B3635\%5D.pdf> Acesso em: 02 out.2020.

MENDES, Sarah de Lima. Tecendo a história das instituições do Brasil infantil. Disponível em:< file://C:/Users/User/AppData/Local/Packages/Microsoft.MicrosoftEdge_8wekyb3d8b 
bwe/TempState/Downloads/6685-Texto\%20do\%20artigo-16818-1-1020150212\%20(1).pdf> Acesso em: 31 agost.2020.

NUNES, Maria Fernanda Rezende; CORSINO, Patrícia; DIDONET, Vital. Educação Infantil no Brasil: primeira etapa da educação básica. Disponível em: <www.histedbr.fe.unicamp.br/revista/revis/revis10/art13_10.html> Acesso em: 02 set.2020.

OLIVEIRA, Gislene de C. Contribuições da psicomotricidade para a superação das dificuldades de aprendizagem. In: SISTO, Firmino Fernandes. (Org.) Atuação psicopedagógica e aprendizagem escolar. 5. ed. Petrópolis: Vozes, 1998.

ROLIM, Amanda Alencar Machado; GUERRA, Siena Sales Freitas; TASSIGNY, Mônica Mota.Uma leitura de Vygotsky sobre o brincar na aprendizagem e no desenvolvimento infantil. Disponível em:<http://brincarbrincando.pbworks.com/f/brincar\%20_vygotsky.pdf> Acesso em: 02 set.2020.

SANTOS, Ana Claudia Siqueira; SILVA, Nascimento Lima Silva. Alfabetização e letramento: dois conceitos, um processo. Disponível em:https://portal.fslf.edu.br/wpcontent/uploads/2016/12/tcc3-6.pdf > Acesso em: 02 set.2020.

SILVA, Benedita da Conceição Mendes; SANTOS, Lilian de Jesus Marques. Disponível em: <https://monografias.brasilescola.uol.com.br/educacao/a-importancialudico-na-educacao-infantil.htm\#indice_4 > Acesso em: 02 set.2020

SOUZA, Lisânias Cornélia. A importância da brincadeira na educação infantil. Disponível em:<https://tede2.pucsp.br/bitstream/handle/18591/2/Lisanias\%20Cornelia\%20de\%2 0Souza.pdf> Acesso em: 31 agost.2020.

VYGOTSKY, L. A formação social da mente: o desenvolvimento dos processos psicológicos superiores. 4ª ed. São Paulo: Martins Fontes, 1991.

VELOSO, Geisa Magela; MACHADO, Claudia Aparecida Ferreira. Jogos e brincadeiras: saberes e práticas de professoras participantes do PNAIC. Disponível em:<

file://C:/Users/User/AppData/Local/Packages/Microsoft.MicrosoftEdge_8wekyb3d8b bwe/TempState/Downloads/28534-Texto\%20do\%20artigo-111607-1-1020190927\%20(1).pdf> Acesso em: 31 agost.2020.

WIKIPÉDIA. Declaração Universal dos Direitos Humanos. Disponível em: <http://pt.wikipedia.org/wiki/Declara\%C3\%A7\%C3\%A30_Universal_dos_Direitos_Hu manos> Acesso em 06 de agosto de 2011

WIKIPÉDIA. Declaração Universal dos Direitos da Criança. Disponível em: <http://pt.wikipedia.org/wiki/Declara\%C3\%A7\%C3\%A3o_Universal_dos_Direitos_da _Crian\%C3\%A7a> Acesso em 07 de agosto de 2011 
Revista Multidisciplinar do Nordeste Mineiro, v.1,

2021/01

ISSN 2178-6925

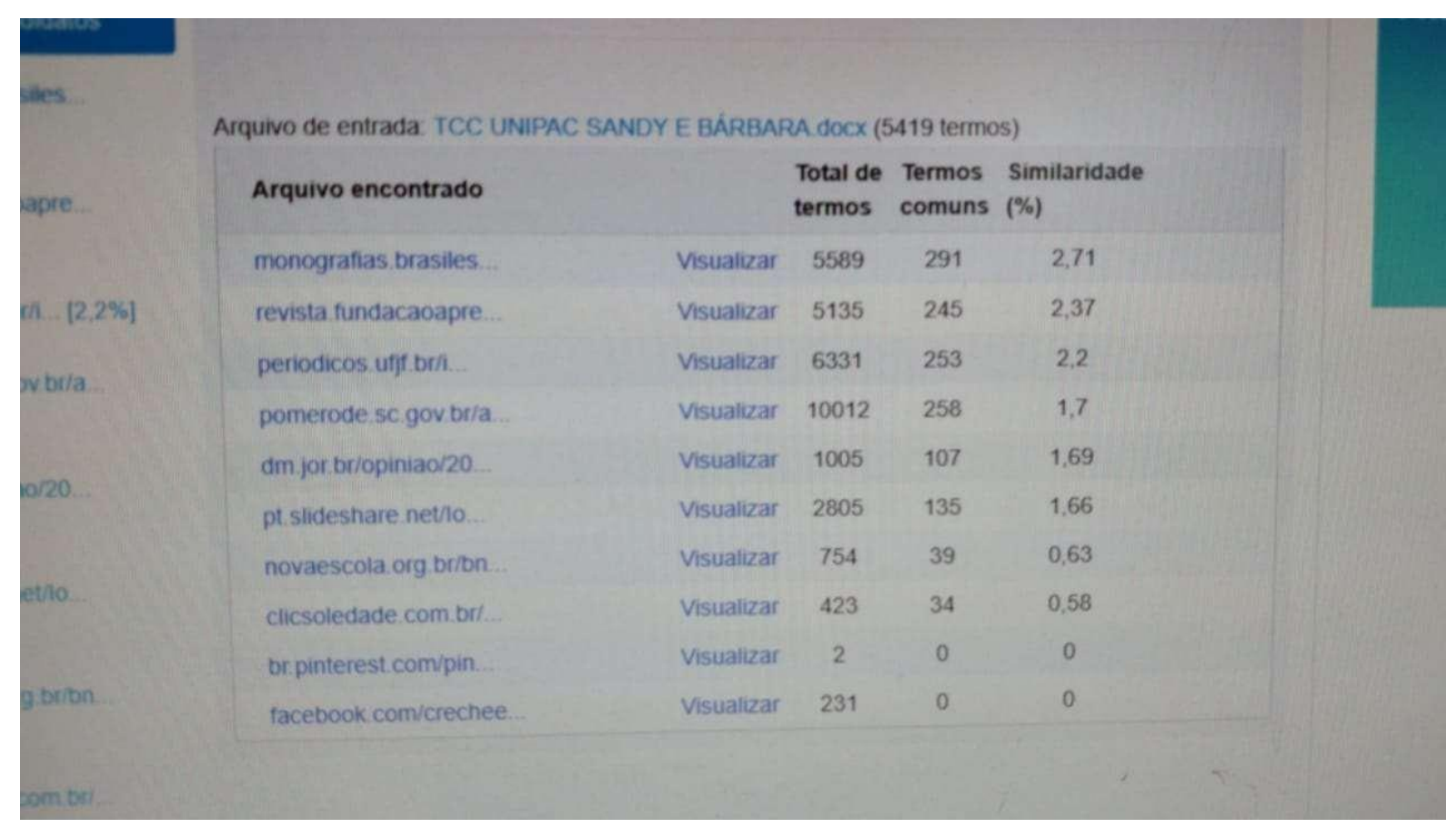


Revista Multidisciplinar do Nordeste Mineiro, v.1, 2021/01

Faculdade Presidente Antônio Carlos de Teófilo Otoni

FICHA DE ACOMPANHAMENTO INDIVIDUAL DE ORIENTAÇÃO DE TCC

Atividade: Trabalho de Conclusão de Curso - Artigo/Monografia.

Curso: Pedagogia Período: $8^{\circ}$ Semestre: $2^{\circ}$ Ano: 2020

Professor (a): Geovana Maria dos Santos Gomes

Acadêmico: Bárbara Costa da Silva / Sandy Kelly Reis Fraga

\section{Tema: AS CONTRIBUIÇÕES DO BRINCAR PARA O DESENVOLVIMENTO DA CRIANÇA NA EDUCAÇÃO INFANTIL}

\begin{tabular}{|c|c|c|}
\hline Data(s) do(s) atendimento(s) & Horário(s) & \\
\hline $31 / 08 / 2020$ & 08:00-09:00 & \$a \\
\hline $30 / 09 / 2020$ & $16: 00-17: 00$ & - traoza \\
\hline $27 / 10 / 2020$ & $16: 00-17: 00$ & 5 \\
\hline $05 / 11 / 2020$ & $17: 00-17: 30$ & Ris's \\
\hline $09 / 11 / 2020$ & $08: 48-10: 45$ & Gandukell \\
\hline
\end{tabular}

As orientações foram realizadas de forma clara, precisa, com pontualidade e compromisso de ambas as partes

Considerando a concordância com o trabalho realizado sob minha orientação, AUTORIZO O DEPÓSITO do Trabalho de Conclusão de Curso do (a) Acadêmico (a): Sandy Kelly Reis Fraga 